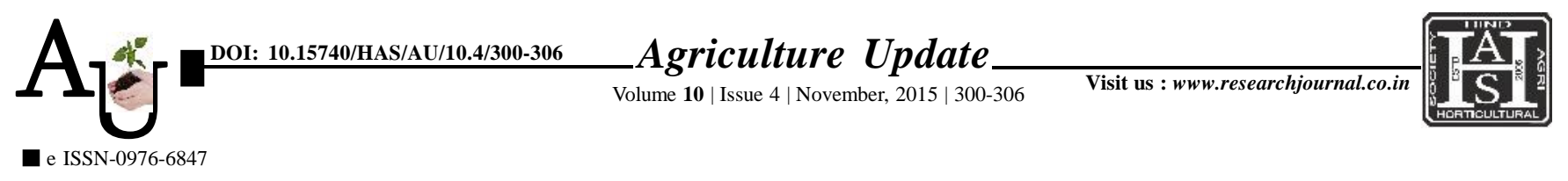

\title{
Research Article: Decomposition analysis and acreage response of chickpea in western Vidarbha
}

\section{VIKRAM SANDEEP, D.H. ULEMALE AND S.S. THAKARE}

Article Chronicle: Received :

30.06.2015;

Revised :

21.09.2015;

Accepted :

07.10 .2015

KeY Words :

Acreage response,

Chickpea,

Decomposition,

Growth rate
SUMMARY : In the present investigation, an attempt was made to study the decomposition and acreage response of chickpea in western Vidarbha. The study was based on time series secondary data on the rainfall, farm harvest price and other data, which were obtained from various Government publications. Nerlovian lagged adjustment model (1958) was used in acreage response analysis based on time series data. The study revealed that the compound growth rate for area and production under chickpea was recorded high during period I in all the districts. During period II, the area, production and productivity of chickpea registered mostly negative growth rates in all the districts. During period III, the compound growth rate for area, production and productivity under chickpea has increased in all the districts of western Vidarbha region. During overall period, the co-efficient of variation and Coppock's instability index for area, production were high in Yavatmal district compared to other districts. At overall period, the area effect (37.44\%) was most responsible factor for increasing production in Amravati division with positive yield and interaction effect i.e., 6.78 per cent and 55.69 per cent, respectively.

How to cite this article : Sandeep, M. Vikram, Ulemale, D.H. and Thakare, S.S. (2015). Decomposition analysis and acreage response of chickpea in western Vidarbha. Agric. Update, 10(4): 300-306. 